\title{
Parceria entre empresa e comunidades tradicionais na Amazônia brasileira: processos contemporâneos de mercantilização da cultura e do meio ambiente
}

\section{Partnership between companies and traditional communities in Brazilian \\ Amazonia: contemporary processes of mercantilization of the culture and the environment}

Jodival Mauricio da Costa - Graduado em Geografia pela UFPA, mestre em Geografia pela UFRGS e doutorando em Ciência Ambiental na USP. Membro do grupo de Políticas Públicas, Territorialidade e Sociedade do Instituto de Estudos Avançados da USP (IEA-USP). E-mail: jodival.costa@usp.br

Patrícia Richetti - Relações públicas e publicitária, mestre em geografia pela Universidade Fedearal de Santa Maria. E-mail: patirichetti@yahoo.com.br

\section{Resumo}

A discussão que segue trata de uma abordagem das comunidades tradicionais amazônidas e sua inserção no processo de globalização pela via da parceria com empresas de cosméticos, no caso a Natura. Nesse aspecto, o objetivo é discutir o processo de valoração da cultura dessas comunidades tradicionais, e sua relação com a questão ambiental, ao serem incorporadas na política socioambiental da empresa. $\mathrm{Na}$ forma como essas relações são produzidas, entendemos que sua projeção no cenário global se dá pela via da mercantilização cultural, fenômeno crescente no atual modelo capitalista. Destarte, o tema é abordado em duas frentes: a primeira diz respeito ao processo de apropriação da cultura produzida por/nessas comunidades pela empresa, partindo, inclusive, da ideia de que o valor cultural emprestado das comunidades tradicionais amazônicas, assim como o conteúdo ambiental aí existente, projeta na empresa uma valoração da sua imagem e, em consequência, do seu produto; a segunda, trata-se da discussão desse tema como um mecanismo de obtenção da renda monopolista, termo trazido para o debate geográfico pelo geógrafo David Harvey. O trabalho é fruto de quatro de anos de pesquisa sobre a ação de empresas na Amazônia.

\section{Palavras-chave}

Globalização. Cultura. Comunidades Tradicionais. Amazônia. Renda monopolista.

\begin{abstract}
The discussion that follows is an approach of traditional Amazonian communities and their integration into the globalization process through partnership with cosmetics company, where the Natura. In this respect, the objective is to discuss the process of assessing the culture of these traditional communities, and their relationship with the environment, in incorporating social and environmental policy in the company. In how these relations are produced, we believe that its projection on the global stage occurs through the commoditization of culture, a growing phenomenon in today's capitalist model. Thus the issue is addressed on two fronts: the first refers to the process of appropriation of culture produced by/in these communities by the company, leaving even the idea that the cultural value of the borrowed traditional Amazonian communities, as well as the environmental content there existing projects in the company a valuation of your image and, consequently, its product and the second, this is a discussion of this topic as a mechanism for obtaining a monopoly rent, brought an end to the debate by geographic geographer David Harvey. The work is the result of four years of research concerning the actions of companies in the Amazon.
\end{abstract}

\section{Keywords}

Globalization. Culture. Traditional Communities. Amazon. Monopoly rent. 


\section{DA ARTE DA RENDA EM CENÁRIOS DE GLOBALIZAÇÃO} NEOLIBERAL

Pode parecer contraditório, que no momento em que experimentamos o sucesso do mundo globalizado para o mercado, a extração de renda monopolista ainda seja uma marca da acumulação de capital. No presente trabalho trazemos alguns pontos para esse debate, considerando que, em virtude da diminuição ou até mesmo eliminação de alguns casos específicos de extração de renda monopolista do passado (como os fatores de localização por conta do acesso ao transporte em tempos pretéritos em que o deslocamento de mercadorias era mais restrito), o processo de globalização atual imprime ao mercado, ao mesmo tempo em que também é resultado desse próprio processo, novas bases de extração de renda monopolista.

Consideramos, aqui, o discurso cultural, da natureza e de regiões estratégicas (consideradas de forma indissociável) como componente singular de extrair renda em cenários de competitividade global. Para tanto, iniciamos com uma discussão sobre a renda monopolista a partir das argumentações desenvolvidas por Harvey (2005), por Marx (2008, 2009) e das argumentações de Foucault (2008) sobre o neoliberalismo. Em seguida, acrescentamos nossas considerações sobre o uso da questão de culturas locais e a crise ambiental como extração de tal tipo particular de renda.

Pode-se questionar o porquê de usar Michel Foucault numa discussão embasada nas ideias de capitalismo de Karl Marx, uma vez que enquanto o primeiro concentra o desenvolvimento do capitalismo no social ou segundo o põe no econômico. No entanto, nossa leitura de Karl Marx não considera que este tenha operado um reducionismo do capitalismo ao nível do econômico, ou seja, submetido unicamente à própria lógica do capital; e não comungamos das argumentações do próprio Michel Foucault de que Karl Marx tenha feito. Mas, não vemos nisso obstáculo para abdicar de uma discussão tão profunda sobre o neoliberalismo quanto a feita por Foucault (2008). Ideias divergentes não deve servir de obstáculo para um dialogo entre os atores.

Algo que se coloca como fundamental no presente momento, marcado por uma certa forma de valorização de culturas locais é como o processo de globalização se relaciona com determinadas localidades e suas formas culturais. E, a partir disso, como essa relação pode implicar em uma forma de extração de renda monopolista. No aspecto geral, considera-se que as rendas monopolistas se configuram pelo controle exclusivo que determinados atores sociais exercem sobre alguns itens que permitem aumentar o seu fluxo de renda por muito tempo, direta ou indiretamente comercializável, e que se caracteriza pelo seu aspecto de singularidade e particularidade, crucial, único e irreplicável (HARVEY, op. cit., p. 222). O autor considera duas situações em que tal processo é mais recorrente.

A primeira situação corresponde ao quadro em que determinados atores sociais conseguem o controle de recursos naturais ou determinada localização e, assim, podem vincular as ações daqueles que necessitam utilizar tais recursos ou usar tal localização aos interesses do seu controlador. Harvey cita o exemplo de um vinhedo que produz vinho de grande qualidade e associa isso à região em que este é produzido, levantando argumentos tais como a qualidade da terra, para emprestar uma singularidade e particularidade à mercadoria. Nessa situação, a renda é consequência do preço monopolista. Já uma versão localizada de tal extração são as centralidades. O mercado imobiliário, por exemplo, vale-se bastante do artifício de amenidades como áreas verdes, facilidade de transporte (como estações de metrô), para obter tais vantagens. Nesse sentido, constituem-se casos indiretos de renda monopolista, pois não se comercializa a terra, o recurso natural ou o local de qualidade singular, mas a mercadoria ou serviço produzido por meio do seu uso.

Num segundo caso, considera-se uma situação de uso direto, pois se tira proveito diretamente da terra ou do recurso. A escassez se cria pela retenção da terra ou do recurso para uso presente, especulando-se sobre valores futuros. É a singularidade da própria mercadoria que, nesse caso, forma a base para o preço monopolista (HARVEY, 2005, p. 222). Não obstante, isso não significa que essas situações se deem de forma isolada, pois frequentemente elas se cruzam.

A categoria renda monopolista carrega, na acepção do autor, duas contradições. A primeira diz respeito ao fato de que mesmo reconhecendo que a singularidade e a particularidade constituem fatores de grande importância para emprestar qualidades especiais a um dado item, o requisito relativo à negociabilidade implica que item algum possa ser tão único a ponto de escapar de um cálculo monetário. Nesse aspecto, quanto mais facilmente negociáveis são tais itens, mais eles perdem condições de gerarem renda monopolista. Assim, para que a renda monopolista possa se materializar é preciso encontrar formas de conservar únicos as mercadorias e os valores. A segunda contradição está relacionada ao modelo neoliberalismo, pois se argumenta que em virtude da grande concorrência 
que fora estabelecida neste modelo, a renda monopolista já não teria como se materializar - pois como os monopólios seriam tolerados? Em outras palavras, o que pesa nessa contradição é a prerrogativa de que a concorrência anularia qualquer forma de monopólio, pois seria a livre concorrência a ditar as regras do jogo.

A argumentação de Harvey (2005) em relação a essas contradições expressa o sentido de que a concorrência não implica, no capitalismo, na falta de monopólios ou oligopólios. Recorrendo a concepções de Karl Marx o autor escreve que toda forma de competição tende para o monopólio ou para o oligopólio. Dentre outros fatores que se pode elencar para tal situação está o fato de que o capitalismo sempre cultiva, de modo ativo, o poder monopolista. O capitalismo não pode existir sem poderes monopolistas e busca, de acordo com cada contexto, formas diferentes para manter sua gênese, e o neoliberalismo não constituiria uma exclusividade ao processo de acumulação capitalista, muito embora, não se possa e nem se deva negar que as condições de acumulação se dão de forma bastante diferenciadas, com novas posturas das empresas e dos Estados.

Foucault (2008, p. 181) argumenta que entre o liberalismo clássico e o neoliberalismo existe uma diferença fundamental - é que para o neoliberalismo, o problema não se trata em saber, da mesma maneira que no liberalismo clássico o que existia era uma estratégia do mercado para arranjar um espaço livre numa sociedade política já dada. Mas “o problema do neoliberalismo é, ao contrário, saber como se pode regular o exercício global do poder político com base nos princípios de uma economia de mercado."

Portanto, o desafio do neoliberalismo é outro, trata-se de atuar num processo de regulação em um período de crise constante e que as ações sociais já são ordenadas de modo a favorecem o próprio mercado. E, nesse aspecto, a globalização neoliberal produz espaços de atuação em que aquilo que pode ser considerado como monopólio no contexto do liberalismo clássico e, talvez, até a primeira metade do século XX, sofre profunda transformação no contexto do neoliberalismo.

Mais interessante ainda é quando esse poder monopolista não aparece sob a forma do controle, mas justamente pelo seu contrário - metamorfoseado numa espécie de liberdade de concorrência. Deixar margem de que todos são livres para chegar aonde desejarem é, talvez, a principal forma de produzir exclusão e monopólio, pois numa situação assim, o poder, como expressa Foucault (1999), não necessariamente se revela, e este é muito mais eficaz quando encontra formas de aparecer sem ser visto. O período atual, provavelmente mais que qualquer outro, oferece essa forma de exercício do poder, pois sob a égide da globalização neoliberal e, principalmente nas duas últimas duas décadas, amparados pela crise ambiental, o capitalismo encontra novas bases de acumulação, em que tenta ocultar não apenas os conflitos ambientais, mas também os sociais.

O valor monetário de uma mercadoria está associado a diversos outros valores que tal produto carrega. Marx (2009, p. 179) escreve que a renda é relativa, isto é, não existe um cadastro pronto, pois para que tal cadastro tenha um valor prático é necessário que sempre se permaneça nas condições da sociedade atual. Nesse sentido, uma das saídas para continuar a gerar renda monopolista, mesmo no cenário atual de globalização, é buscar em que valores o capitalismo se apoia para continuar gerando um tipo de renda diferenciada, que possa garantir vantagens competitivas. De fato, trata-se, como tão bem discutiu Lefebvre (2002), da própria sobrevivência do capitalismo.

Nosso entendimento é de que o fator concorrencial, assim como os "avanços" trazidos pelo processo de globalização na área de transporte e de comunicação, acabou por interferir diretamente, como já comentado acima, em formas pretéritas de obtenção de renda monopolista - principalmente aquelas advindas de vantagens de localização, em virtude de privilégios na circulação dos produtos.

Não obstante, o argumento de Marx (2009) de que o capitalismo e seus mecanismos de acumulação de capital devem ser entendidos no contexto em que se desenvolvem, é valido para pensarmos que novas formas de obtenção de renda monopolista se materializam no período atual. Nesse sentido, ela não deve ser procurada, exclusivamente, nos casos em que os atores econômicos tenham um exclusivo de mercado, ou seja, uma reserva de venda de seus produtos por conta das singularidades que possui. Mesmo que isso possa acontecer, entendemos que, dentre outras, uma forma em que tal mecanismo de obtenção de renda vem se desenvolvendo é justamente pela inserção nas mercadorias de valores culturais, ambientais e regionais, valendo-se de fatores como a crise ambiental e culturas tradicionais para emprestar valor diferenciado ao produto, ganhando singularidade e particularidade num espaço-tempo marcado pela gestão "inconteste" da crise ambiental, no qual as práticas culturais que carregam um estatuto condizente com esse período-crise ganham uma licença social privilegiada. 
Isso ao vai ao encontro da máxima dos governos neoliberais, de que é preciso intervir nas condições do mercado e não no seu mecanismo. Em outras palavras, trata-se de manter a gênese do capitalismo, mas, metamorfosear-se de acordo com as condições do período. Nesse sentido, Foucault (2008, p 191) argumenta que uma das ações fundamentais do neoliberalismo - as ações ordenadoras -, não consiste em agir diretamente nos mecanismos de mercado, como agir nos preços, por exemplo, mas trata-se justamente de atuar na moldura - na população.

O monopólio pode consistir, nesse novo cenário, não um controle dos preços, mas uma posição privilegiada no mercado, pelo valor associativo a questões culturais, ambientais e regionais do produto. Nesse sentido, o monopólio ou oligopólio não deve ser pensado no seu sentido semântico, mas como materialização privilegiada da renda - uma espécie de garantia -, em cenários de grande competição.

Nesse contexto, destacamos três pontos de grande importância no que tange à constituição de privilégios na extração de renda no período atual:

O poder do capital simbólico coletivo das comunidades tradicionais amazônidas.

O poder do capital simbólico do produto advindo de base ambientalmente sustentável.

Alguns consumidores, hoje, considerando aqueles que de fato se constituem como consumidores das mercadorias não básicas, sentem-se satisfeitos por estarem consumindo produtos que carregam o slogan de "ambientalmente correto" e "socialmente responsável". Há vários grupos empenhados no discurso desse tipo de mercadoria - com destaque para as ONGs, associações de consumidores, artistas, etc. Consideramos que essas atitudes constituem uma via de mão-dupla: se por um lado esses grupos chamam a atenção para a importância da questão ambiental atualmente, por outro, eles atuam como dispositivo de formação de um tipo de padrão de consumidor o que, simultaneamente, implica num tipo padrão de produto - um item discursivo do capital na extração da renda monopolista.

Também não discutimos intencionalidade, mas o resultado que tal discurso produz no mercado global de determinados produtos e suas repercussões como processo de formação de base para acumulação de renda monopolista. O período atual joga com duas forças que causam impacto na sociedade - a histórica exclusão social, fruto extremamente acirrada no capitalismo e que, nas últimas décadas, tornou-se um dos carros-chefe no discurso das empresas e a "recente" crise ambiental.

O que o neoliberalismo requer do Estado, como argumenta Foucault (2008, p. 199) é que o objetivo é agir não nos mecanismos de mercado, mas intervir em sua sociedade, em sua trama e em sua espessura, para que os mecanismos concorrenciais possam ter o papel de regulador. Atualmente, as normas ambientais atuam como legitimadoras de regras que são postas por conta da crise ambiental. A questão, é que a crise ambiental abriu um novo caminho de regulação via-mercado - “os negócios verdes", que não são uma questão de livre iniciativa. Assim, como regulação, não temos necessariamente um governo econômico, mas um governo de sociedade. $\mathrm{O}$ que deve constituir o ente regulador nesse caso não é tanto a troca de mercadorias, mas o mecanismo da concorrência. (2008, p. 201). Trata-se de um ordenamento econômico-jurídico da sociedade, centrado não nas forças de produção, mas nas relações de produção.

Assim, o econômico no neoliberalismo não significa que o mercado atue sem nenhuma regulação. Pelo contrário, significa justamente que pela regulação das relações sociais acaba-se por se regular, a favor da garantia da concorrência, o próprio mercado. Um conjunto de atividades reguladas, cujas regras têm níveis, formas, origens, datas e cronologias totalmente diferentes (FOUCAULT, 2008, p. 225). Isso só pode se dá à medida que uma moldura institucional garante sua existência.

Nesse sentido, a concorrência neoliberal não tem o objetivo de suprimir processos de formação de obtenção de rendas de tipo exclusivas. A questão é que esse processo passa a existir em novas bases, e o próprio sentido de monopólio sofre mutação no período atual. Um desses mecanismos pode ser pensado, por exemplo, num tipo de norma que tem como objetivo garantir singularidade e particularidade a um tipo de produto, pelas condições impares de sua produção, como em virtude da crise ambiental.

A história do capitalismo carrega essa estrutura econômico-institucional. Não tem como pensar acumulação de capital sem essa moldura institucional que ordene as relações sociais, porque assim se ordena as relações de produção que garantem o funcionamento dos mecanismos no capitalismo. Assim, voltamos à afirmação de que o que está em questão nesse objeto político é o problema da própria sobrevivência do capitalismo. E, nesse aspecto, suas metamorfoses estruturantes devem ser pensadas dentro desse processo de re-invenção, adaptação e, inclusive, de incorporação das contradições como mecanismo de sobrevivência, mantendo a gênese de garantir a acumulação. Não obstante, isso não implica, nem se deve jamais reduzir o capitalismo à lógica econômica de reprodução do capitala finalidade de uma dada atividade não reduz o processo a essa causa, que implica 
uma totalidade em constante movimento muito mais ampla. Isso implica, por exemplo, que se forjando um novo funcionamento institucional se possa superar os efeitos de crise, impasses, contradições (FOUCAULT, 2008).

Nem o Estado, nem o mercado, num modelo neoliberal operado sob a égide do Estado de direito dizem de modo particular às pessoas o que elas devem fazer, como o devem e como devem consumir; isso se faz apenas em sentido geral. O aparato institucional, por meio da ordenação social, produz esse tipo de mecanismo. É a mecânica da natureza que desenvolve tal mecanismo? Não, é a mecânica do poder político-econômico. De acordo com as intervenções que são chamadas a fazer em cada período, pelas condições que o período apresenta de emergência dessas mudanças, a moldura institucional produz novos dispositivos de ordenamento da sociedade.

\section{A NATURA E SEUS PRODUTOS AMAZÔNICOS: DISCURSO SOCIOAMBIENTAL E SINGULARIDADE DAS MERCADORIAS}

Vimos na parte anterior que os capitalistas cultivam de modo ativo o poder monopolista. Por meio disso, eles realizam um controle de longo alcance sobre a produção e o marketing, para estabilizar o ambiente empresarial (HARVEY, 2005). No caso da extração de renda monopolista, o investimento em campanhas publicitárias veste-se de uma importância ímpar. Como lembra Harvey (2005), a mão visível da empresa, como Chandler a denomina, foi muito mais importante para a geografia histórica capitalista do que a mão invisível do mercado, muito alardeada por Adam Smith, e muito alardeada, nos últimos anos, como poder diretriz da ideologia neoliberal da globalização contemporânea.

Cada vez mais, as empresas investem na publicização de seus valores, com o objetivo de criar uma imagem frente aos atores que compõem suas cadeias produtivas e também para si mesmas, já que se trata de produzir uma cultura que a identifique. Isso implica considerar não apenas os consumidores, mas toda a cadeia produtiva. Pela mão do marketing, ferramenta que se veste de importância singular no período atual, as empresas expõem suas políticas empresariais e sua cultura. Nesse aspecto, algo fundamental, hoje, no discurso das empresas, é o componente social e ambiental de suas ações. Dito de outra forma, há uma tendência de as empresas que venham a conseguir maior sucesso entre o público - a contar pela aceitação de seus produtos e o lucro que consigam acumular -, serão aquelas que cultivam valores socioambientais. E, claro, isso já é uma realidade.

No caso tomado como exemplo aqui, da Natura, não é objetivo deste trabalho discutir a conduta da empresa perante as comunidades tradicionais, nem se sua conduta ambiental constitui preocupações ambientais legítimas ou não. Também não é nossa finalidade fazer uma análise dos fatores que proporcionaram o crescimento da empresa. Reservamos-nos o direito de usá-la exclusivamente como exemplo de extração de renda no cenário de competitividade global, em virtude da singularidade e particularidade que suas ações socioambientais alcançam no universo mercantil, uma vez que a própria empresa ressalta a importância que seu compromisso com as comunidades locais de onde atua (neste caso, a Amazônia) e o desenvolvimento sustentável de suas atividades ocupa no sucesso que a mesma tem conquistado no mercado - os tão alardeados "negócios sustentáveis".

Portanto, o leitor não deve esperar encontrar no presente trabalho uma discussão sobre a empresa, pois apresentaremos dados resumidos, que nos permitam relacionar a política da empresa ao real objetivo da nossa discussão - o uso de comunidades tradicionais, da crise ambiental e de regiões estratégicas, do ponto de vista de tal crise, como conquista e/ou conservação de mercado.

Como escrito anteriormente, o marketing da empresa é fator de grande importância para obter sucesso, e a Natura, que está no mercado há 40 anos, tem se mantido fiel a esse princípio. De acordo com a própria empresa (NATURA, 2006), a partir de 2006, os investimentos nesse setor começaram a trazer mais resultados, não apenas dentro do Brasil, mas também em outros países, com destaque para suas vendas no Chile, Argentina e Peru, de acordo com pesquisa de percepção do consumidor feita no final do exercício. No Brasil, pesquisa mostra que 74\% dos consumidores consultados dão nota máxima à empresa em Avaliação Global da Marca (NATURA, 2009).

Pelas campanhas veiculadas nos meios de comunicação e nos relatórios anuais divulgados pela Natura, encontra-se uma empresa que tem como marca uma imagem de responsabilidade socioambiental de sua produção (NATURA, 2006, 2007, 2008, 2009). Entre os valores publicados como suas crenças estão a união entre as pessoas como forma de construção de uma sociedade mais solidária e o desenvolvimento com sustentabilidade ambiental (NATURA, 2009).

No caso da Amazônia, o alcance de que as atividades desenvolvidas nessa região sejam feitas por um modelo de desenvolvimento sustentável chegou a 
proporções globais. De tal emergência, algumas empresas que atuam no espaço amazônico já atentaram para a importância que essa visibilidade significa como vantagem competitiva na globalização neoliberal. Assim, pelo peso que a referida região ocupa nesse cenário, tanto no Brasil, quanto no exterior, o mercado já leva em consideração as condições em que os produtos de lá procedentes são produzidos. Destarte, se hoje já se pode considerar tal importância, o que dizer das perspectivas de mercados futuros. A tendência de que futuramente as exigências de condições ambientais se tornem um ponto cada vez mais significativo na hora de escolher que produto comprar é cada vez maior. E, nesse caso, a Natura tem cultivado ao máximo o discurso da responsabilidade social e ambiental de suas ações na região, não apenas para produtos daí procedentes, mas como uma marca da empresa. Dentre outros que possam ser elencados, optamos por destacar três princípios do discurso da empresa.

- Discurso em relação à inclusão social - uso do patrimônio intelectual tradicional. A empresa tem tornado o elo com as comunidades onde atua um dos pilares de sua missão. Na Amazônia, fez pareceria com comunidades de vários estados, das quais destacamos: a Cooperativa Mista dos Produtores e Extrativistas do Rio Iratapuru (COMARU), que conta com um total de 32 famílias cooperadas, todas do município de Laranjal do Jari, no Amapá. Parceira da Natura desde o ano 2000, além dos recursos recebidos pela coleta do produto, no caso a castanha-dopará, a comunidade recebe uma porcentagem pelo uso da imagem nas propagandas da Natura (NATURA, 2010). No Amazonas, a empresa mantém uma parceria com a Cooperativa do Desenvolvimento Agroextrativista do Médio Juruá (CODAEMJ), criada com o apoio da Universidade Federal do Amazonas, e atualmente conta com 300 famílias e de lá é extraída a Andiroba usada nos produtos da empresa (NATURA, 2010). O cupuaçu utilizado pela empresa é extraído principalmente no estado de Rondônia, através de parceria com o Projeto Reca, que inclusive já conta certificação orgânica (NATURA, 2010). Uma das parcerias feitas no Pará é com o Movimento das Mulheres das Ilhas de Belém (MMIB), e destas a empresa adquire um tipo de erva usada em seus produtos - a Priprioca. Por conta do uso de alguns desses produtos e do relacionamento com comunidades tradicionais, algumas ações envolvendo a empresa estão correndo no Ministério Público (MACHADO, 2009).
- Atrelado ao discurso do desenvolvimento social na Amazônia, está o de desenvolvimento sustentável. Em todas essas parecerias a empresa cultiva o valor do desenvolvimento sustentável na Amazônia.

- Discurso em relação à Amazônia - "floresta em pé e não no chão." Compondo uma relação indissociável com os dois itens anteriores, esse discurso valoriza a ideia de conservação da biodiversidade amazônica, e através do seu portal Natura Ekos, a empresa disponibiliza não apenas suas ações diretas de desenvolvimento sustentável, como disponibiliza documentos sobre a temática biodiversidade e expõe seus valores no tratamento da problemática ambiental (NATURA, 2010).

Nesse sentido, de acordo com os relatórios e anúncios da Natura nos meios de comunicação (2009), o grande avanço que a empresa tem experimentado nas últimas décadas, mas em especial no início deste século, deve-se muito a sua política de tratamento com as comunidades onde atua e pelo desenvolvimento sustentável de sua produção; no caso da Amazônia, com o saber tradicional e conservação ambiental de uma das regiões mais estratégicas do ponto de vista da crise ambiental. Tanto as comunidades amazônidas, quanto à própria Amazônia, têm uma carga de simbolismo de grande impacto nas relações de mercado, justamente pelo fato de ter alcançado tão grande importância nas relações sociais.

Algo que credita o que estamos afirmando é, como dito anteriormente, a acuidade que a empresa dá ao uso do termo comunidades tradicionais amazônidas e à própria Amazônia ao anúncio de seus produtos (principalmente no caso da Linha Natura Ekos). A produção que a mesma realiza em outras localidades aparece nos relatórios como fator demonstrativo, como fator importante, inclusive porque a política da empresa é corporativa, mas não recebe tratamento de marketing como o empregado aos produtos fabricados na Amazônia ou com matéria-prima de lá procedente, assim como o tipo de trabalho empregado.

Não temos um estudo, nem sabemos se é possível tal feito, que permita medir o alcance do valor simbólico cultural e ambiental cultivados pela Natura no imaginário dos consumidores, a ponto de significar, tal valor, um exclusivo de renda. A empresa não faz esse diagnóstico, nem faz tais afirmações. Mas, como já dito, pelo espaço que isso tem ocupado em sua política de marketing, entendemos que esse fator tenha importância fundamental para a própria empresa, assim como não dá para ignorar que empreste um certo estatuto de identidade ao produto. 
Nesse aspecto, o mais importante não é se a contabilidade da empresa consegue ou não quantificar tal medida. O sucesso de mercado que uma empresa alcança em valores monetários é resultado, em grande parte, de sua política empresarial. E, nesse caso, é um erro desconsiderar o peso que a carga simbólica representa nisso. O mercado está imerso nas relações sociais, e estas são carregadas de valores. Cada vez mais empresas como a Natura jogam com isso, fazem marketing de seus valores sociais e ambientais e produzem e/ou cultivam dispositivos de valoração.

Em um mundo marcado pela forte concorrência, como o atual, produzir marcos de distinção e acúmulo de capital simbólico continua. O que muda são os marcos de distinção e suas formas de uso. A Natura pode (e assim tem procedido) alegar singularidade e particularidade de seus produtos, pelo tratamento que tem dado ao uso do patrimônio intelectual das comunidades tradicionais amazônidas (valorização dessas comunidades) e de conservação ambiental.

Isso não implica na afirmação de que as pessoas vão passar a consumir unicamente por isso. Consumidores não são meros receptáculos de mercadorias, não pensantes e manipulados. Pessoas consomem produtos porque descobrem nestes alguma utilidade pra si. E, nesse sentido, a importância do valor cultura e ambiental não pode estar apenas no produto, mas principalmente nas pessoas. Daí porque não se trata apenas de produzir mercadorias "socioambientalmente corretos", mas principalmente do desenvolvimento de dispositivos de ordenamento social que levem em consideração esses valores. Nesse ponto, cultura e meio ambiente tornam-se a passos largos valores cada vez mais significativos nas relações sociais. Assim, os efeitos discursivos que estão em jogo são variados, e de grande importância no significado que tal produção pode obter e garantir algum tipo de exclusividade de renda.

No tocante à Amazônia, a lógica da Natura não se diferencia de atividades anteriores. O que se está pensando, como é comum à própria empresa, é o lucro da indústria. Por que o desenvolvimento da Amazônia sempre tem que ser pensado por alguma forma de apropriação dos valores locais por interesses externos? Primeiro, dos seus recursos materiais, hoje, da produção de recursos simbólicos e sua materialização nas mercadorias. Dizemos produção de recursos simbólicos porque a forma cultural amazônida, como anunciada pelos atores econômicos, não existe para essas comunidades - é uma produção social cultivada no/para esse imaginário social. As comunidades locais existem para si mesmas na sua simplicidade (ou complexidade como entendam), mas, como representação simbólica, só podem existir para os outros. E, nesse sentido, são valores forjados nas relações sociais de produção. O mesmo se aplica ao uso da Natureza. Nem a cultura, nem a Natura, são passiveis de apropriações em si mesmas - toda apropriação é também uma invenção; o que não deve ser tomada como sinônimo de falácia.

\section{CONSIDERAÇÕES FINAIS}

Podem questionar, acerca das nossas argumentações, que atribuir o recurso da renda monopolista ao tratamento dado por empresas às comunidades locais onde atuam e à valorização do meio ambiente seja operar um reducionismo econômico dessas iniciativas empresariais. Recorrendo ao próprio Harvey (2005), afirmamos que não podemos, nem temos a intenção, de evitar que desenvolvam tais argumentos.

Não obstante, desejamos ter conseguido chamar atenção para o fato de que o capitalismo, justamente por não dever ser reduzido ao econômico, sempre vai procurar desenvolver dispositivos de ordenamentos sociais que permitam criar formas de garantir, numa relação dialética, a concorrência e a geração de singularidades e particularidades que desemboquem em algum tipo de exclusividade de renda. E, nesse caso, nossos argumentos de que o uso do patrimônio cultural de comunidades tradicionais e o discurso da conservação ambiental podem gerar exclusividade de renda para empresas, principalmente como potencialidade futura, reside justamente na importância que esses itens vêm ocupando nas relações. Em especial, à questão da conservação ambiental, uma vez que o peso das comunidades tradicionais nesse arranjo deve-se em grande parte ao tipo de relação que estas cultivam com a natureza.

Podem questionar, os defensores dos "negócios verdes", de que nossos argumentos não se justificam porque tais negócios são produzidos pela livre iniciativa; e que essas empresas são peças importantes, dado o estágio de degradação ambiental. Novamente reiteramos que não podemos evitar tais afirmações, nem negamos que tais condutas empresariais não tenham sua importância nesse cenário de degradação ambiental. No entanto, tratando disso dentro do próprio mercado (isto é, considerando os efeitos do mercado para os próprios capitalistas), temse algo que o "mercado verde" não é - é aberto. Tal mercado possui um forte 
processo de ordenação por meio das normas ambientais desenvolvidas como forma de regulação e de legitimação dessas ações. Entrar nesse mercado não depende exclusivamente do desejo de fazê-lo, porque é preciso entrar no jogo das regras e normas aí estabelecidas. Não dá pra sermos inocentes a ponto de acreditarmos que em virtude do quadro de degradação ambiental existente (produzido pelas próprias relações que permanecem atualmente), exista um altruísmo capitalista substituindo o jogo dos poderes.

A mercantilização da cultura e da natureza, transformação destas em capital simbólico, é um dos maiores indicadores de acumulação de capital da nossa época. Pensar nisso em atividades desenvolvidas na Amazônia tem um peso significativo. Não porque seja a Amazônia mais importante do que outras regiões brasileiras ou outras localidades do mundo, porque cada localidade pensada para si mesma não possui parâmetro de comparação; mas porque no imaginário mundial existe uma produção social desta região que já é, e talvez seja mais ainda num futuro próximo, capaz de exercer grande influência na acumulação de capital.

Assim, que nesse cenário de globalização neoliberal, o capitalismo encontre em fatores como estas estratégias de diferenciação, é uma tendência iminente. Algo diferente nessa nova forma de produzir singularidade e particularidade dos produtos é que estas qualidades não se encontram num recurso que o ator detenha como alguma forma de propriedade, mas trata-se, justamente, de uma apropriação simbólica, no caso do meio ambiente das comunidades tradicionais. Não é a força de trabalho das comunidades amazônidas empregada na produção dos produtos da Natura, nem o produto extraído da floresta em si que tem significado como exclusividade - trata-se de uma questão de produção de sentido; é o peso cultural da palavra comunidade tradicional amazônida atrelada ao discurso do desenvolvimento sustentável e preservação da região que está em questão. Não fazemos aqui nenhuma apologia à produção sem preocupação com as questões socioambientais, mas, pelo mesmo lado, não podemos deixar de chamar a atenção para o fato de que tais iniciativas constituem justamente uma nova estratégia do capital de garantir sua sobrevivência, como bem discutiu Lefebvre (2002).

\section{REFERÊNCIAS}

FOUCAULT, M. Nascimento da Biopolítica: curso dado no Collège de France (1978-1979). Edição de Michel Senellarr. Tradução de Eduardo Brandão. Revisão da tradução de Claudia Berliner. São Paulo: Martins Fontes, 2008 (Coleção Tópicos).

Em Defesa da Sociedade: curso dado no Collège de France (19751976). Tradução de Maria Ermantina Galvão. São Paulo: Martins Fontes, 1999. (Coleção Tópicos).

HARVEY, D. A arte da renda: a globalização e a transformação da cultura em commodities. In: HARVEY, D. A produção capitalista do espaço. São Paulo: Annablume, 2005. p 219-239. (Coleção Geografia e Adjacências).

LEFEBVRE, H. La Survie du Capitalisme: La reproduction des rapports de production. 3. ed. Paris: Economica, 2002.

MACHADO, A. Natura e novamente o debate em torno de acesso a biodiversidade e os territórios de comunidades tradicionais. Disponível em: <http://verdeamazonia.wordpress.com/2009/03/04/natura-e-novamenteo-debate-em-torno-de-acesso-a-biodiversidade-e-os-questionamentos-sobre-osterritorios-de-comunidades-tradicionais>. Acesso em: 25 jun. 2010.

MARX, K. Contribuição à Crítica da Economia Política. Tradução e introdução de Florestan Fernandes. 2. ed. São Paulo: Expressão Popular, 2008.

A metafísica da economia política. In: MARX, K. Miséria da Filsofia: resposta à Filosofia da miséria do Sr. Proudhon. Tradução de José Paulo Netto. São Paulo: Expressão Popular, 2009. P. 119-192.

NATURA. Relatório Anual, 2006.

Relatório Anual, 2007.

Relatório Anual, 2008.

Relatório Anual, 2009.

NATURA. www.naturaekos.com.br. Acesso em: 25 jun. 2010.

Texto submetido à Revista em 25.6.2010

Aceito para publicação em 30.11.2010 
